Вестник Новосибирского государственного педагогического университета

3(25)2015 www.vestnik.nspu.ru ISSN 2226-3365

(C) Ю. В. Пушкарёв, Е. А. Пушкарёва

DOI: $10.15293 / 2226-3365.1503 .05$

\title{
УДК 316.3/.4
}

\section{ЗНАНИЕВАЯ ПАРАДИГМА В ОБЩЕСТВЕННОМ РАЗВИТИИ: ОСНОВНЫЕ КОНЦЕПЦИИ}

\author{
Ю. В. Пушкарёв, Е. А. Пушкарёва (Новосибирск, Россия)
}

\begin{abstract}
В статье выявляются основные концепции понимания знания в истории и современности, соотношение значений знания и информачии. Отмечается, что знание сегодня понимается учеными все более широко: не только в историко-культурологическом, науковедческом аспектах, но также как интеллектуальная основа новейших, инновационных технологий. Сегодня именно вокруг знания как объекта познания формируются новые научные дисциплины, исследовательские области, научные направления и сложные конгломераты по изучению систем, форм знания, гибридных образований в сфере знаний, разрабатываемых как в теоретической, так и в прикладной формах. Вопросы о том, что такое знание, в чем его смысл, что необходимо знать, зачем (для чего) знать, волновали человечество уже с тех пор, как только оно стало способно философствовать. В статье анализируются подходы к пониманию знания и информации в истории философии и науки. Научное знание в современном общественном развитии становится основой организачии людей, необходимым условием их совместной деятельности. Оно во все большей степени приобретает значение интегрирующего начала в общественной жизни, приходя на смену традиционным формам объединения людей.
\end{abstract}

Ключевые слова: знание, информация, знаниевая парадигма, общество знания, информаичонное общество, когнитивная философия, знаниеведение, история философии и науки.

Знание сегодня понимается учеными все более широко: не только в историкокультурологическом, науковедческом аспектах, но также в актуально-прогностическом и оптимологическом плане, как интеллектуальная база новейших, инновационных технологий XXI в. - гуманитарного, социального и технико-технологического направлений. Современная система образования предполагает интеграцию гуманитарной и естественнонаучной знаниевых парадигм [6].

Неслучайно, что сегодня именно вокруг знания как объекта познания формируются новые научные дисциплины, исследовательские области, научные направления и сложные конгломераты по изучению систем, форм знания, гибридных образований в сфере знаний, разрабатываемых как в теоретической,

Пушкарёв Юрий Викторович - кандидат философских наук, доцент кафедры права и философии, Новосибирский государственный педагогический университет.

E-mail: pushkarev73@mail.ru

Пушкарёва Елена Александровна - доктор философских наук, профессор кафедры права и философии, Новосибирский государственный педагогический университет.

E-mail: pushkarev73@mail.ru 
так и в прикладной формах (Б. С. Грязнов, Ю. И. Колюжов, В. А. Садовничий, В. С. Степин, Е. В. Ушакова $[2 ; 8 ; 14 ; 16])$.

Современными исследователями устанавливается соотношение изменений общественного сознания в условиях появления в современном обществе огромного количества информации; рассматривается и критически осмысливается феномен информационного перенасыщения [7]. Анализируется познавательная деятельность в формах gnosis и cognitio, выявляются их различия с точки зрения места и роли в жизни человека, объектов исследования, мотивации субъектов деятельности, содержания $[1 ; 10-11]$.

Ставя вопросы в данной исследовательской области, следует определить, что необходимо понимать под знанием и как соотносятся знание и информация. В философском энциклопедическом словаре знание определяется как форма существования и систематизации результатов познавательной деятельности человека [19]. Одновременно, в теории науки, знание - результат процесса познания действительности, получивший подтверждение в практике; адекватное отражение объективной реальности в сознании человека (представления, понятия, суждения, теории) [4, с. 113]. Знание объективизируется знаковыми средствами языка, т. е. фиксируется в знаках естественных и искусственных языков. Категория «информация» определяется (от лат. informatio - изложение, разъяснение) как сведения, передаваемые устным, письменным и др. способами (с помощью условных сигналов или технических средств).

Вопросы о том, что такое знание, в чем его смысл, что необходимо знать, зачем (для чего) знать, волновали человечество уже с тех пор, как только зародилась философия. На разных этапах истории человечество отвечало на него по-разному, пройдя путь от знания (в единственном числе) к знаниям (во множественном числе). На ранних этапах развития общества знание носило общий характер. Сегодня знания в силу необходимости стали глубоко специализированными. Раньше не употреблялось такое понятие, как «человек, обладающий знаниями», а говорилось: «образованный, ученый человек». Другими словами, человек широкой эрудиции, обладающий достаточными знаниями, чтобы вести разговор или писать на общие разнообразные темы и при этом не сведущий в той или иной конкретной практической деятельности. По мнению И. М. Ильинского, в современном университете «образованных людей в традиционном понимании могут счесть лишь дилетантами» [5, с. 191].

Сократ полагал, что цель знания заключается в самопознаниии и саморазвитии. При этом результаты служат самому человеку. Протагор же утверждал, что цель знания уметь сказать что нужно и как нужно. Эпоху Сократа и Платона немецкий философ К. Ясперс назвал «осевым временем». С той поры «человек осознает бытие в целом» [21, c. 33]. Осознание бытия развивалось на приращении знания, не имеющего ограничений с той сократовской поры, когда сомневающийся человек критически отнесся к мифологии, авторитету мифических богов («идеалов культуры», по Ницше) и героев. «Осевое время» открыло в человеке самого человека. Письменность закрепила устную информацию, накопленную в «доистории» и переданную поколениям после «осевого времени».

В эпоху Средневековья система образования включала в себя грамматику, логику и риторику, т. е. также была направлена на развитие умения соразмерно говорить. В течение более двух тысяч лет именно такая трактовка знания имела определяющее значение для западной системы образования. Не следует, 
конечно, отождествлять средневековый «текст» культуры с современным понятием «информация», хотя причинно-следственная связь между ними прослеживается. Средневековая культура теологизирована. Теологические факультеты в средневековых университетах были самыми престижными. Истинным знанием считалось то, которое давалось через Откровение.

Сначала Возрождение, потом Просвещение в Европе осуществили десакрализацию и секуляризацию в культуре по типу человеческого мышления, основывающегося на рациональном познании. «Мифологическая неопределенность, имевшая «космическое оформление» (А. Лосев), сменилась христианским теоцентризмом, эманацией Бога как непосредственного Творца, приведшего Хаос к Порядку. Но и сакрально-оккультное «обуздание» космической неопределенности сменилось рационально-научной, а потом и социально-институциональной оформленностью бытия» [3, с. 85-86].

Научные революции неизменно вызывали конструктивные изменения в системе знания, влияя на мировоззренческое освоение и осмысление законов окружающего мира, поскольку одной из наиболее общих и существенных закономерностей познавательного процесса является движение знания от философии к естествознанию и от естествознания к философии [12, с. 75-79]. Печатный станок, как техническое явление, и книга, как духовный «текст» культуры, задали вектор информационного движения в мире и поставили (неосознанно по тому времени) проблему техники и информации, цивилизации и культуры.

В итоге, по словам И. М. Ильинского, «пресс времени, процесс разделения труда, особенно бурно происходивший в последние столетия, раскололи некогда целостное зна- ние о природе, человеке и обществе на множество областей знаний. Сегодня нет знания, есть много знаний, нет науки, есть множество наук» [5, с. 193].

Незавершенность дискуссии о природе информации, признание информологии в качестве науки, а «информационной реальности как содержания мира» по мнению Н. М. Чуринова [20, с. 78-79], свидетельствуют о тотальном отрицании мистики (анимизма, тотемизма), мифа («космической телесности», «кентавра»), откровения («теодицеи») и об утверждении информации в качестве «главного ключа» Вселенной - объективной реальности с двумя атрибутами: материального и идеального. Традиционный спор между «материалистами» и «идеалистами» заканчивается на признании «информационной реальности» и глобальной коммуникации [3, с. $85-86]$.

Понятие «информация» имеет сложный и многоплановый характер. Предлагая различные трактовки понятия «информация», ученые применяют как минимум три подхода: содержательный, количественный и знаниевый. Так, в работах А. Д. Урсула, Н. Винера, Л. Брюллюэна присутствует содержательный подход к пониманию информации. Например, Н. Винер представляет информацию как «содержание, полученное из внешнего мира в процессе приспособления к нему» (Н. Винер). К. Э. Шеннон - использует количественный подход: «информация - это содержание сообщения, понижающего неопределенность некоторого опыта с неоднозначным исходом; убыль связанной с ним энтропии является количественной мерой информации» [15].

При исследовании проблем образования понятие «информация» часто используется по аналогии с понятием «знание». Например, в математическом энциклопедическом словаре 
(ред. Ю. В. Прохоров), «информация - это субъективное понятие, синонимичное понятию “знание”». Известны работы, в которых выделены существенные различия в содержании этих понятий. Например, разграничение понятия информации и знания по признаку подчиненности - «понятие информации является родовым по отношению к понятию знания, а видовым отличием понятия знания является его связь с сознанием субъекта». Знание - субъективный образ объективной реальности, т. е. адекватное отражение внешнего и внутреннего мира в сознании человека в форме представлений, понятий, суждений. Кроме того, еще Л. Брюллюэн отметил, что «мы определяем информацию как результат выбора $<\ldots>$ мы полностью игнорируем человеческую оценку информации <..> Другими словами, мы определяем информацию как нечто отличное от знания, для которого у нас нет количественной меры» [15].

Категория «информация» с сер. XX в. становится общенаучным понятием, включающим обмен сведениями не только между людьми, но и человеком-автоматом, автоматом-автоматом, а также обмен сигналами в растительном и животном мире [13]. Информация не существует сама по себе, а только через определенный носитель. Как специально научная категория «информация» - одно из основных понятий кибернетики [9].

По мнению Н. М. Чуринова, предложение «космического, диалектического, информационного проекта науки» [20, с. 78-79]), как перспективного философского метода, в отличие от универсалистского (в информационно развитых странах), относит понятие об информации все же в область гуманитарного знания, а не технократического. Иначе говоря, информацию нельзя редуцировать до ее технических носителей, т. е. компьютеров электронной связи. Компьютер, как техниче- ское средство, нейтрален по отношению к человеку. А вот информация, получаемая с помощью компьютера, усваивается пользователем с позиции его индивидуальных интересов, обусловленных социальной средой существования, конкретным обществом «информационной реальности» [3, с. 90]. Таким образом, исследователи акцентируют внимание на антропологическом понимании сути информации и ставят eе, как социальнофилософскую категорию, в зависимость от категорий культуры и цивилизации. Также в современных исследованиях подчеркивается, что современная система образования предполагает интеграцию гуманитарной и естественнонаучной знаниевых парадигм [6, с. 17].

Проанализировав различные представления о знании и информации, в том числе, об изменении этих понятий в истории развития общества, необходимо остановиться на двух основных определениях, соотносящих категории «знание» и «информация», и адаптирующих их к современной социальной ситуации. В первом случае, знание в широком смысле - это весь массив информации, которым располагает общество на определенном временном отрезке его развития. И тогда термин «знание» оказывается, по существу, синонимом совокупной информации общества (или какой-либо отдельной социальной общности).

Во втором случае, знание в более узком смысле понимается как некая определенная часть совокупной информации, обладающая специфическим качеством, под которым следует понимать позитивный, жизненно важный смысл, заключенный в соответствующей части информации. С этой позиции, информация бессмысленного или разрушительного времяпровождения, соответствующих видов жизнедеятельности уже не является знанием, понимаемым как фундаментальная основа 
социального бытия. Данный аспект понимания соотношения категорий «знание» и «информация» наиболее значим и актуален для настоящего исследования.

Проблема информации как знания человека и человечества исследуется в работах Е. В. Ушаковой и др. [8; 16-18], которые считают, что основное содержание информации быть необходимым знанием для человека (индивидуальное знание), общества (общественное знание) и человечества (общее знание). А знание, в первую очередь, необходимо для того, чтобы служить человеку и человечеству основанием для верной практической деятельности в межличностных, социальных и социоприродных взаимодействиях. Другими словами, знание в современном обществе - это информация, имеющая практи- ческую ценность, служащая для получения конкретных результатов. То, что сегодня называют знанием, постоянно доказывает свою значимость и проверяется на практике. Причем, результаты проявляются вне человека - в обществе, экономике, развитии самого знания. Для получения значимых результатов в любой области требуются знания высокоспециализированные.

В итоге, научное знание в современном общественном развитии становится основой организации людей, необходимым условием их совместной деятельности. Оно во все большей степени приобретает значение интегрирующего начала в общественной жизни, приходя на смену традиционным формам объединения людей.

\section{СПИСОК ЛИТЕРАТУРЫ}

1. Булкин А. П. Познание - наивысший аффект: еще раз о когнитивной компетенции // Проблемы современного образования. - 2013. - № 4. - С. 51-64.

2. Грязнов Б. С. Логика, рациональность, творчество. - М.: 1982.

3. Замышляев В. И. Гуманитарные смыслы информационного общества // Философия образования. - 2005. - № 1. - С. 85-92

4. Ивин А. А., Никифоров А. Л. Словарь по логике. - М.: Владос, 1997. - 250 с.

5. Ильинский И. М. Образовательная революция. - М.: Изд-во Московской гуманитарносоциальной академии, 2002. - 592 с.

6. Калянов А. В. Теория «пространственновременного континуума» с позиций естественнонаучной знаниевой парадигмы // Вестник Московского государственного университета культуры и искусств. - 2012. - № 2. - С. 17-22.

7. Коломейцев И. А. Общественное сознание в информационном потоке // Наука, техника и образование. - 2014. - № 2 (2). - С. 68-73.

8. Колюжов Ю. И., Ушакова Е. В. Содержательная стратегия обучения: знаниеведческий аспект // Вестник Томского государственного университета. - 2005. - № 45. - С. 77-82.

9. Костюк В. Н. Информация как социальный и экономический ресурс. - М.: Магистр, 1997 $48 \mathrm{c}$.

10. Майер Б. О. Когнитивные аспекты современной философии отечественного образования: монография. - Новосибирск: Изд-во СО РАН, 2006. - 276 с.

11. Майер Б. О. Эпистемологические аспекты философии образования: монография. - Новосибирск: Изд-во НГПУ, 2005. - 213 с.

12. Москаленко А. Т. Динамика знаний и образования в условиях научно-технической революции // Философия образования. - 2002. - № 5. - С. 75-79. 
13. Новейший философский словарь / сост. А. А. Грицанов. - Мн.: Изд. В. М. Скакун, 1998. 896 c.

14. Степин В. С. Философская антропология и философия науки. - М., 1997.

15. Урсул А. Д. Проблема информации в современной науке. - М.: Наука, 1975. - 386 с.

16. Ушакова Е. В. Системно-философское содержание современной научной картины мира (мировоззренческо-методологический аспект): дисс. ... докт. филос. наук. - Иркутск, 1999.

17. Ушакова Е. В. Системная философия и системно-философская научная картина мира на рубеже третьего тысячелетия: в 2 ч. - Барнаул, 1998.

18. Ушакова Е. В. Знаниеведение и управление: моногр. - Барнаул: Изд-во АлтГУ, 2006.

19. Философский энциклопедический словарь. - М.: ИНФРА-М, 2000.

20. Чуринов Н. М. Совершенство и свобода: Философские очерки. - Красноярск, 2001. 432 c.

21. Ясперс К. Смысл и назначение истории - М.: Политиздат, 1991. - 527 с. 
DOI: 10.15293/2226-3365.1503.05

Pushkarev Yury Viktorovich, Candidate of Philosophical Sciences, Associate Professor of Faculty of Law and Philosophy, Novosibirsk State Pedagogical University, Novosibirsk, Russian Federation.

E-mail:pushkarev73@mail.ru

Pushkareva Elena Aleksandrovna, Doctor of Philosophical Sciences,

Professor of Faculty of Law and Philosophy, Novosibirsk State

Pedagogical University, Novosibirsk, Russian Federation.

E-mail: pushkarev73@mail.ru

\title{
KNOWLEDGE PARADIGM IN SOCIAL DEVELOPMENT: BASIC CONCEPTS
}

\begin{abstract}
The article reveals the basic concepts of knowledge in understanding the history and contemporary form, the ratio of the values of knowledge and information. It is noted that the knowledge of today is understood by scientists more widely: not only in the historical, cultural, and scientific aspects, but also as the intellectual basis of new, innovative technologies. Today it is around knowledge as an object of knowledge, the formation of new scientific disciplines, research areas, research areas and complex conglomerates for the study of systems, forms of knowledge, hybrid entities in the field of knowledge developed in both theoretical and applied forms. Questions about what is knowledge, what is its meaning, what should I know why (why) know, was already troubled mankind since as soon as it was able to philosophize. The article analyzes approaches to the understanding of knowledge and information in the history of philosophy and science. Scientific knowledge in contemporary social development becomes the basis of people's organization, a necessary condition of their joint activities. It is increasingly becoming a value integrator start in public life, coming to replace the traditional forms of bringing people together.
\end{abstract}

\section{Keywords}

Knowledge, information, knowledge paradigm, knowledge society, information society, cognitive philosophy, study of knowledge, history of philosophy and science

\section{REFERENCES}

1. Bulkin A. P. Cognition - affect higher: once again about cognitive competence. Problems of modern education. 2013, no. 4, pp. 51-64.

2. Gryaznov B. S. Logic, rationality, creativity. Moscow, 1982.

3. Zamyshlyaev V. I. Humanities meanings of the information society. Philosophy of education. 2005, no. 1 , pp. $85-92$

4. Ivin A. A., Nikiforov A. L. Dictionary of logic. Moscow, Vlados Publ., 1997, 250 p.

5. Ilinskiy I. M. Educational revolution. Moscow, Moscow humanitarian-social Academy Publ., 2002, $592 \mathrm{p}$.

6. Kalyanov A. V. The theory of "space-time continuum" from the standpoint of scientific knowledge paradigm. Bulletin of Moscow state University of culture and arts. 2012, no. 2, pp. 17-22. 
7. Kolomeitsev I. A. Public consciousness in the flow of information. Science, technology and education. 2014, № 2 (2), pp. 68-73.

8. Kolosov Y. I., Ushakov E. V. Meaningful learning strategy: Danielewski aspect. Bulletin of the Tomsk state university. 2005, no. 45, pp. 77-82.

9. Kostyuk V. N. Information as a social and economic resource. Moscow, Master Publ., 1997, 48 p.

10. Mayer B. O. Cognitive aspects of the modern philosophy of national education. Monograph. Novosibirsk, SB RAS Publ., 2006, 276 p.

11. Mayer B. O. Epistemological aspects of philosophy of education. Monograph. Novosibirsk, Novosibirsk state pedagogical University Publ., 2005, 213 p.

12. Moskalenko A. T. Dynamics of knowledge and education in the scientific and technological revolution. Philosophy of education. 2002, no. 5, pp. 75-79.

13. The newest philosophical dictionary. Ed. A. A. Grichanov. Minsk, V. M. Skakun Publ., 1998, $896 \mathrm{p}$.

14. Stepin V. S. Philosophical anthropology and philosophy of science. Moscow, 1997.

15. Ursul A. D. The problem of information in modern science. Moscow, Nauka Publ., 1975, 386 p.

16. Ushakov E. V. System-philosophical content of the modern scientific picture of the world (world Outlook and methodological aspect). Irkutsk, 1999.

17. Ushakova E. V. Systematic philosophy and systematic-philosophical scientific picture of the world at the turn of the third Millennium. In 2 parts. Barnaul, 1998.

18. Ushakov E. V. Study of Knowledge and management. Monograph. Barnaul, Publishing house of the University, 2006.

19. Encyclopedic dictionary of philosophy. Moscow, INFRA-M Publ., 2000.

20. Curenow N. M. Perfection and freedom: Philosophical essays. Krasnoyarsk, 2001, 432 p.

21. Jaspers K. The Meaning and purpose of history. Moscow, Politizdat Publ., 1991, 527 p. 